\title{
Structural Modelling of a Monocoque Closed Integral Sedan Car Body
}

\author{
Ahmed Khtab \\ Automotive Department \\ MTC \\ Cairo, Egypt
}

\author{
Mohamed Abd El-Moneim \\ Machine Design \& Production Department \\ MTC \\ Cairo, Egypt \\ Metwally Mohamed \\ Automotive Department \\ MTC \\ Cairo, Egypt
}

\begin{abstract}
This The car body structure is a highly redundant structure with more than one load path and the sharing of the load is a function of the component relative stiffness. In static stress analysis, only the loads that cause elastic strains and stresses in the structure are studied in such a way that there is no yielding of the material or joint failure . Practical experience suggests that a vehicle structure which is strong enough to endure the maximum dynamic loads, which occur sporadically, will also have sufficient resistance against repeated dynamic forces at less than their average value (fatigue loading). Then the key factor in the design analysis process is the determination of The Dynamic Load Coefficient' which can be used in the static analysis. [1]
\end{abstract}

The structural stress analysis of the car body is carried out by the discussion of:

1- The concept of the load-bearing structure.

2- The determination of the input loads.

3- Implementation of different theories for the static loading of the structure and the strength of the body and its joints.

The first part of the structural stress analysis is the study of the load-bearing structure. The general description of the car body structural components under consideration in this paper and its three subassemblies are discussed followed by the descriptions of the structural model idealization.

Keywords - Monocoque, Car Body Structural Analysis, Finite Element Analysis, Thin-walled structure, Optimization Analysis.

\section{INTRODUCTION}

The main objectives in car structural design are to obtain a minimum weight design which makes the best use of material by arranging for each member to support as near as possible its maximum load potential, to make the structure direct and continuous by providing an unbroken path from point of application to point of reaction, to minimize weight; by spreading concentrated loads as much as possible; which are efficiently distributed to react applied load with the minimum redundancy, to avoid buckling of the thin sheet materials in monocoque structure type, and to provide passenger protection in accidents. [1]

Although the modern passenger car, due to aerodynamic and styling requirements has surfaces with high curvature, the structure behind these surfaces can be approximated to components or subassemblies that can be represented as plane surfaces. [3]
The- Integral (monocoque) structure is that type of structure where the all bodywork, except the door and hatches, are load carrying elements, so obtaining lighter integral body/chassis structure with less Hysteresis effect in the unloading curve than the ladder frame due to slippage between the body \& chassis at the mounting points obtaining a more lighter and stronger car, as shown in Fig 1 [4]

Modeling process, which is considered as the major part in structural stress analysis, is obtained by representing the physical car body as an idealized structural model valid for applications of different suitable structural analysis theories to ensure the continuity for the load path through the structure, the integrity of the structure, and that the structure is capable of transferring different types of loads within allowable stress range of the material with a factor of safety.

The idealized representative structural model of the principal internal structural load carrying members is obtained so as to give a simple and yet accurate representative idealization of a generic real sedan car body structure [2]. This idealization is then applied on a real existing saloon car "Nasr DOGAN 1.6 liter " to obtain its structural model. The crosssectional properties and gravimetric analysis need to be specified in the model as a part of the idealization of vehicle body structural model and to be used in the stress analysis that depends mainly on these cross-sectional properties.

\section{METHOD OF APPROACH}

The vehicle body structure is considered to consist of three subassemblies in series (Frontal part, Central (passenger compartment) part, and Rear part). Both the front-end and the rear-end assemblies should have relative lower stiffness than the central part to form the crumple zones in case of collision, [1],[5],[6]

\section{Maintaining the Integrity of the Specifications}

The template is used to format your paper and style the text. All margins, column widths, line spaces, and text fonts are prescribed; please do not alter them. You may note peculiarities. For example, the head margin in this template measures proportionately more than is customary. This measurement and others are deliberate, using specifications that anticipate your paper as one part of the entire proceedings, and not as an independent document. Please do not revise any of the current designations. 
I. PREPARE YOUR PAPER BEFORE STYLING

Before you begin to format your paper, first write and save the content as a separate text file. Keep your text and graphic files separate until after the text has been formatted and styled. Do not use hard tabs, and limit use of hard returns to only one

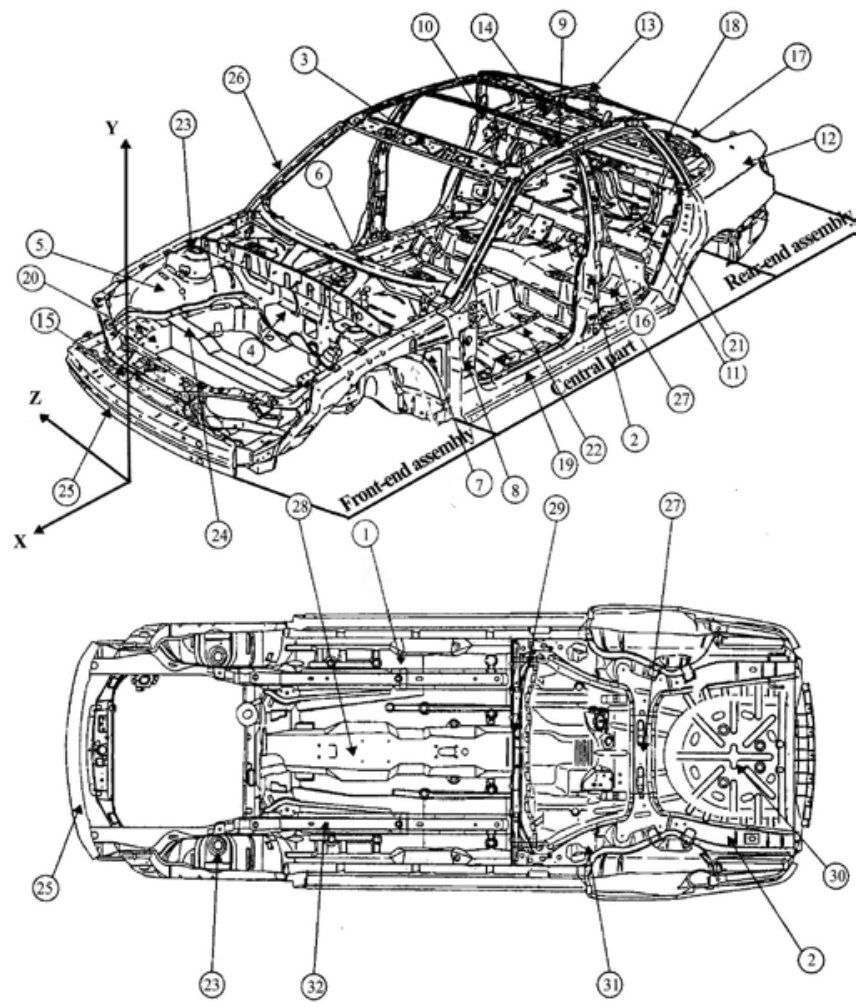

Fig . 1. Body shell assembly for a saloon monocoque closed integral structure.
1 Underbody assembly.

3 Windscreen rail assembly.

5 Fr. wheel panel assembly.

7 Cowl side lower brace.

9 Roof panel assembly.

11 Rear bulkhead brace assembly

13 Rear window UPR rail.

15 Radiator panel assembly.

17 D-post.

19 Sill panel.

21 Rear wheel arch assembly.

23 Valance complete assembly.

25 Front bumper.

27 Rear seat panel.

29 Rear seat cross-member.

31 Rear suspension support.
2 Body side frame assembly.

4 Cowl and dash panel assembly.

6 Windscreen rail assembly.

8 Lower A-pillar.

10 Roof bow assembly.

12 Rear quarter panel assembly.

14 Rear cowl assembly.

16 Central pillar (BC-post).

18 Rear quarter assembly.

20 Front side member assembly.

22 Main floor assembly.

24 Front cross member.

28 Central (transmission) tunnel.

30 Spare wheel well.

32 Longitudinal rail.
26 Upper A-pillar.

The front-end assemblies made up from: the two front side wheel panel assemblies which are connected to the front bulkhead and enclosed by the front cowl (or dash panel) at the rear and at the front by the radiator panel assembly, while the engine cross member assembly is a transverse beam that transfers the engine's weight to the longitudinal members of the front-end panel assembly. It is attached to the main floor panel at the toe panel, and by two lower supporting forks.
The central part (passenger compartment) comprises of the main floor panel assembly, side frame, and roof panel. The bulkhead towards the front and rear complete the box-like form. The curved shape of the roof panel prevents to be in a lozenge (going out of alignment in a diamond shape). Side frame assemblies reinforce the floor pan along the sill sections which consist of the A-post, the BC-post, the D-post, and therear quarter section

The rear-end assembly consists of the rear wheel arch integrated with quarter section, the rear seat heel board (rear bulkhead) forming a closed torsion box with boot floor and rear panel assembly.

The following are the steps of the idealized representative structural model for the principal internal structural load carrying members, which give a simple yet accurate representative idealization of a generic real sedan passenger car body structure [7].

1 - The idealized structure is a combination of Frameworks (such as the edges of larger openings as Doors, Windows) and Shell constructions (which are combinations of Beam sections and Skin panels, in which the skin plays a major part in carrying loads and the beams to take up the concentrated loads) that must be represented by Thin-Walled Shell Structures in the final design stage, and by a simplified one during the first stage as Structural Surfaces.

2 - The side frame is a flat stiff frame, then one shear panel is sufficient to take up the reaction at the upper front and rear bulkheads as shown in Fig.2 [8]

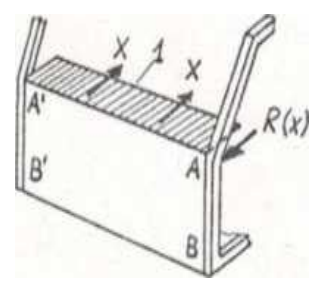

Fig .2. The front bulkhead stiffened with one auxiliary structural surface

3 - The introductions of the forces from the front suspension into the front bulkhead are through the valance with built-up horizontal panels

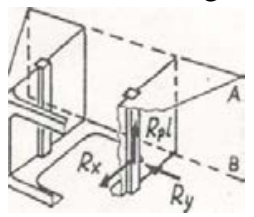
as shown in Fig.3. [3]
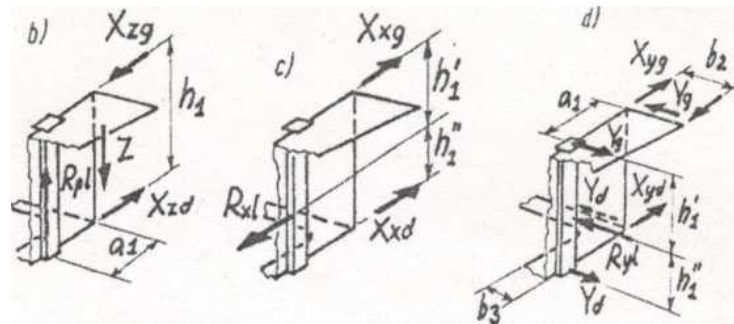

Fig.3. Introduction of forces into the front bulkhead by means of a built up wings; b- vertical load, c-longitudinal load, d-Side loads Showing the internal shear forces, and the corresponding reactions on the surrounding shear panels. 
4 - The base element of a closed structure is the side-frame [AB-C-D-E-F] which transfers bending, have 6-times degree of redundancies as shown in Fig.4. [3]

5 - Side frame with load bearing panel (D-post) l-D-E-J to compensate the decreased bending stiffness of windscreen pillar and also through increasing the remaining sections of the passenger car frame structure as shown in Fig.4. [3]

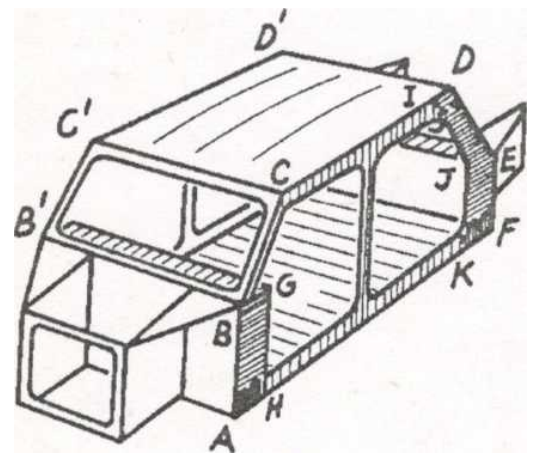

Fig.4. Idealization of closed integral private car body structure with a side frame of load bearing panel l-D-E-J (UPR D-pillar)

6 - The longitudinal member of the front-end panel assembly will be extended under the floor panel to the first crossmember, and will be treated as a cantilever beam on two supports as shown in Fig.5. [4]

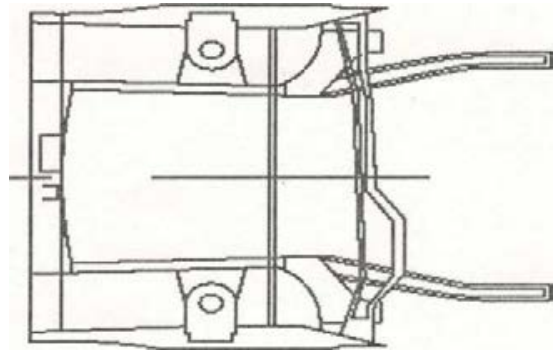

Fig.5. Front-end panel assembly, obtained by AutoCAD vr.2017

7 - The B-C pillars are being reinforced at the points of attachment to the sill and the roof by a central stiffener to form a torsion box to improve the strength and safety during torsion and collision. It's also used to assist with the roof curvature in enhancing the roof panel resistance and the buckling stress, as shown in Fig.6., [4]

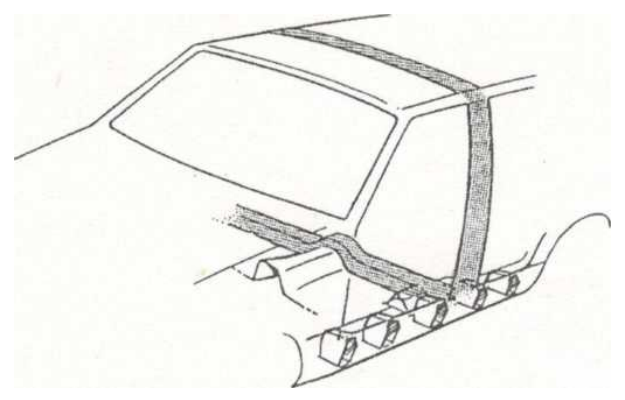

Fig.6. Enhancement the strength of the structure in the form of closed ring.
8-There are several areas that are 'closed-boxlike' structure that will be connected to the side frame which will provide additional torsional stiffness to the overall structure, namely: 1-the engine and luggage compartments, and 2-cowl and footwell assembly (the region enclosed by the front bulkhead, cowl, lower A- pillar, and floor) as shown in Fig.7. [6]
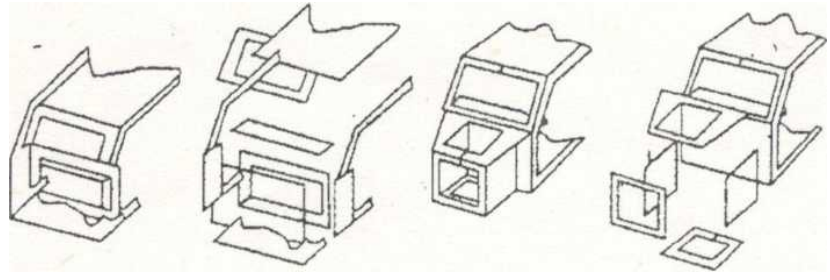

Fig.7. Torsion stiffening by "boxing" some localized regions of car body

9- The stiffness of the roof is built in by the curvature given to it by forming press, while the reinforcement, consisting of small metal strips, serves to stiffen the front and rear edges.

10 - The body of the car is classified into three (or more up to five) subassemblies in series, which are (Frontal part, Central (passenger compartment) part, Rear part) as shown in the Fig..8. [4] For structure in series, the overall torsional stiffnessis given by:

$$
1 / K=1 / K_{1}+1 / K_{2}+1 / K_{3}+1 / K_{4}+1 / K_{5} \text { Eqn }
$$

Thus it's very important to have sub-assemblies with correct load-path design and sufficient stiffness and the connections between them are structurally sound to obtain a well tensional stiffness structure.

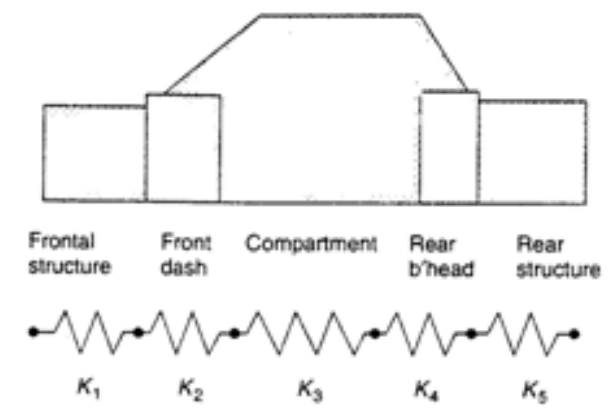

Fig .8. Structure represented as a series of sub-assemblies.

11 - The upper rail of the frontal part is positioned to run directly to the side frame to minimize or bypassing the torsion on the parcel shelf (the front cowl) as shown in Fig.9. [6]

12 - Determine which elements of the structure are to be included in the analysis for overall strength and which for local strength and identify all the load-bearing structure elements of the car body before the analysis is made, and neglect the set of elements which transfer up to $10 \%$ of loads as a limited accuracy required for design calculations. [3] 


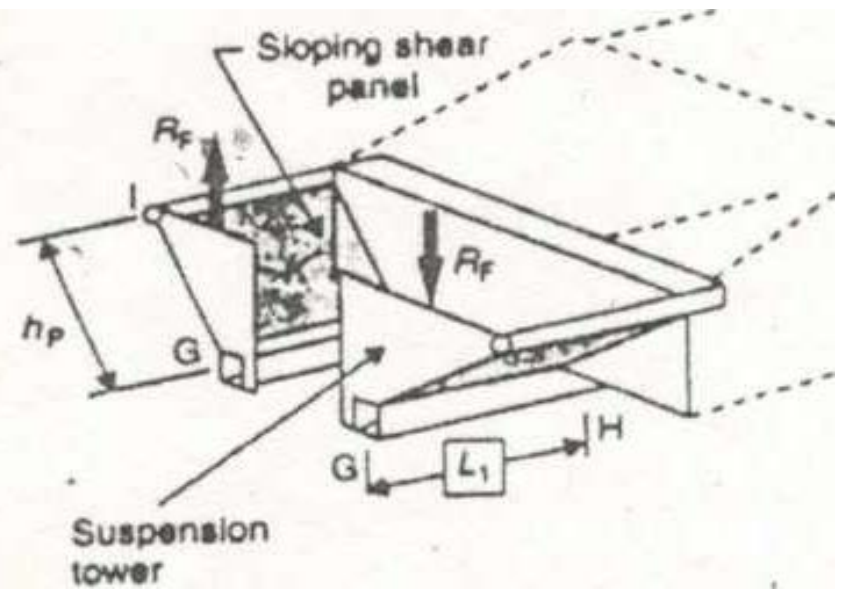

Fig .9.Sloping the wheel panel assembly

13 - Reinforcements of a floor by grillages are used only in bending case, but in torsion case it has no significance in a closed structure because the main effect is coming from the floor panels being in shear. [2]

14 - The major grillage members (which are used to stiffen the floor against out-of-plane loads) in the passenger compartment floor consist of: 1- the transmission tunnel, 2one or more cross-members, 3 - the rockers (sills) as part of the side-frame, 4- the bulkheads at the ends of the compartments. Most of load will be conducted by the crossmember straight to the side frames because of using a very stiff cross-members and a flexible tunnel member, as shown in Fig. 10. [6]

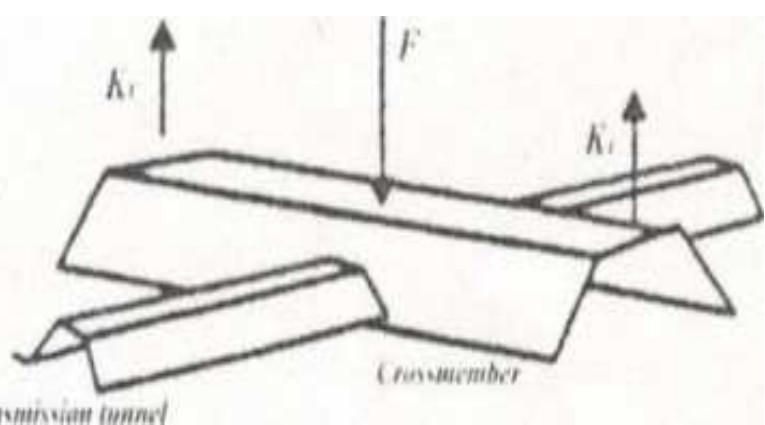

Fig. 10. Stiff cross-member and flexible tunnelfloor arrangement (load transmitted to sides).

15- Three-Dimensional representative structural model idealized representative structural model of the principal internal structural load carrying members is obtained so as to give a simple idealization of a generic real sedan car body structure. This idealization is then applied on a real existing saloon car "Nasr DOGAN 1.6 liter" to obtain its structural model Fig. 11.

16- Fig .12 shows the "Nasr DOGAN 1.6 liter" car body structural model, implementing different loading cases imposed on the car structure and applying different stress analysis theories using different program packages.

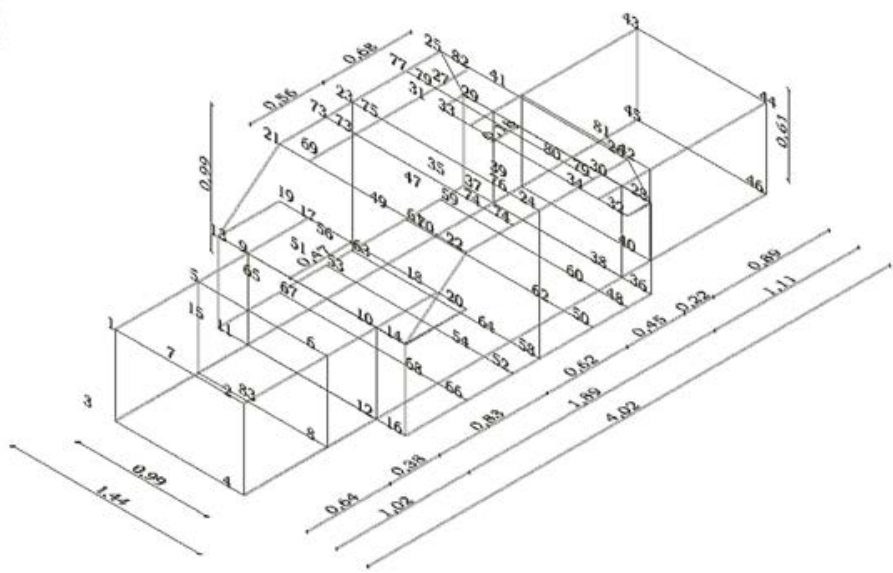

Fig. 11.Three-Dimensional representative structural model idealization for ageneric.

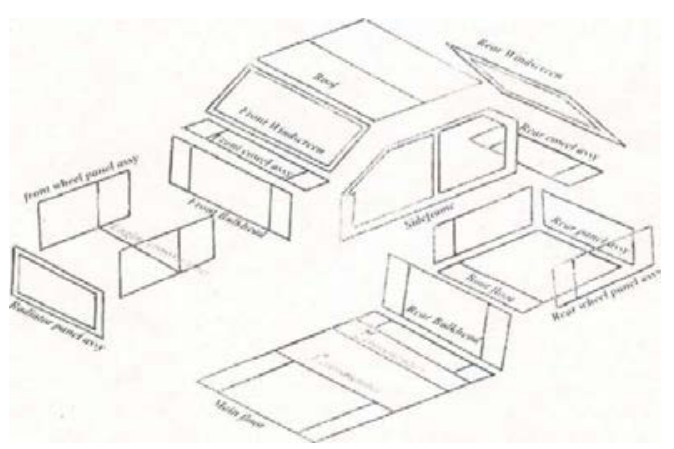

Fig .12. "DOGAN" car body structural model, implementing different loading cases imposed on the car structure and applying different stress analysis theories using different program packages.

Studying the meshing effect on the Finite Element Method (FEM) model to ensure the credibility of the obtained results. The convergence of the solution to an extent that ensuring sufficient element mesh for accurate results maintaining less time consuming. This will be done by making three models with different meshing stages as follows:

1- The coarse or the original model with (83) nodes, as shown in Fig. 13.

2- The intermediate mesh model with (147) nodes.

3- The fine mesh model with (453) nodes.

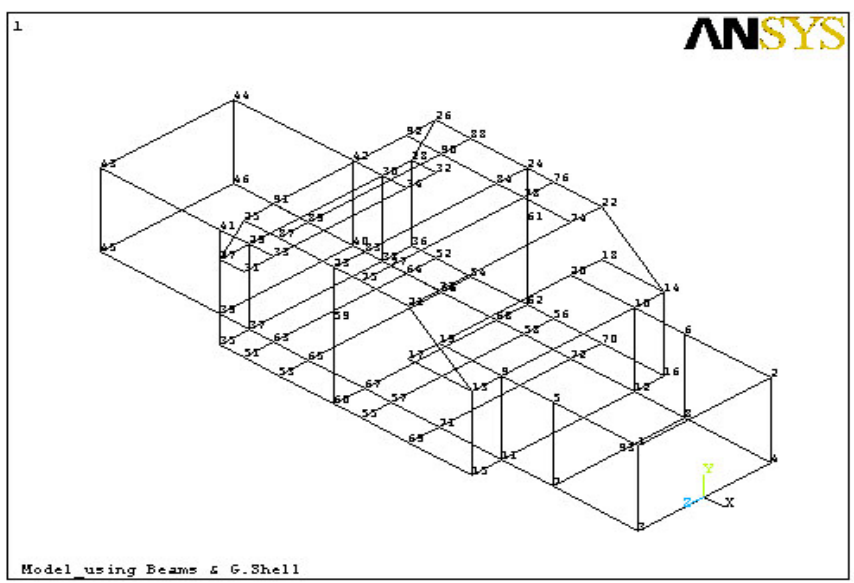

Fig.13. 3D model FEM idealization using general shells and beams. 
Investigating the effect of changing the type of fixations (strained DOF) of the structural model on the obtained results on the above three models by changing the two rear contact points to be with roller support with one DOF constraints instead of simply supported contact points.

Performing structural optimization process; to get the optimal construction under different constraints (strength, deflections, and stiffnesses) that is capable of carrying the required loads and meets all specified requirements criteria with a minimum component weight for both bending and torsion cases; by using the suitable optimization method, defining the structural model properties in terms of parameters from which design variables may be selected, selecting the design variables from beam and shell thicknesses, and specifying the state variables that serves constraints to the design. Comparing the total car torsional stiffness; calculated automatically by a batch file throughout the optimization analysis process; with the more generalized formula for closed body structure deduced by C.J.Cooke to validate the structural analysis process. [9]

\section{DISCUSSION OF THE RESULTS}

Effect of type of fixation and the degree of meshing on the obtained results

The comparison of the obtained results from different meshing stages showed a convergence of the deflection components at all nodes as going through from coarse to fine mesh stages. There are some local areas in which the deflections at the corresponding nodes, especially the vertical components, have high values namely: the main floor assembly, B-pillar beam, and the roof assembly. It is noticed that all these nodes are in the passenger compartment because there is no intermediate vertical shear panels. So, making a fine mesh at these areas will be reflected on the results and get a clear picture on their behavior.

\section{Optimization results}

A comparison was made for the best feasible set of the optimization data files; that satisfy all specified constraints within allowable limits of Design Variables (DVs) and producing the minimum weight; obtained from both the Torsion and the Bending Cases. Then selection of the DVs that satisfy both the Bending and Torsion cases, which converge to the nearest integers that could be used as a sheet metal thickness, and running the program to obtain the model with the best selection of DVs that are reliable at the worst operating conditions and also satisfy all stiffness constraints. Results of the sensitivity analysis of the optimization processes are shown in Table 1 . The table shows a comparison between the starting, best optimization in bending and torsion, and the manual combined optimization model for the most governing DVs.
Table 1.Comparison between the starting, best optimization in Bending and Torsion, and the manual combined optimization model for the most governing DVs.

\begin{tabular}{|c|c|c|c|c|}
\hline DVs and SVs & Starting & $\begin{array}{c}\text { Best } \\
\text { torsion }\end{array}$ & $\begin{array}{c}\text { Best } \\
\text { Bending }\end{array}$ & $\begin{array}{c}\text { Final } \\
\text { selection. }\end{array}$ \\
\hline Beam thickness\# 1(m) & 0.001 & 0.00176 & 0.00135 & 0.0018 \\
\hline Beam thickness\# 2(m) & 0.0015 & 0.00149 & 0.00162 & 0.0015 \\
\hline Beam thickness\# 3(m) & 0.002. & 0.00146 & 0.00079 & 0.0015 \\
\hline Beam thickness\# 4(m) & 0.0025 & 0.0005 & 0.0005 & 0.002 \\
\hline Beam thickness\# 5(m) & 0.0015 & 0.00139 & 0.00123 & 0.0014 \\
\hline Shell thickness\# 1(m) & 0.001 & 0.001 & 0.001 & 0.001 \\
\hline Shell thickness\# 2(m) & 0.002 & 0.00149 & 0.00131 & 0.0015 \\
\hline Shell thickness\# 3(m) & 0.0025 & 0.00071 & 0.0008 & 0.002 \\
\hline Shell thickness\# 4(m) & 0.003 & 0.00096 & 0.0005 & 0.0025 \\
\hline Total car volume (nr3) & 0.04504 & 0.03975 & 0.034314 & 0.04509 \\
\hline $\begin{array}{c}\text { Torsional stiffness, } \\
\text { calculated (N-m/deg) }\end{array}$ & 16876 & 20201 & - & 19526 \\
\hline $\begin{array}{c}\text { Torsional stiffness, } \\
\text { Cooke (N-m/deg) }\end{array}$ & 14686 & 20483 & - & 19582 \\
\hline Total strain energy. & 11.903 & 10.003 & 15.11 & 10.581 \\
\hline Mid-span deflect., (m) & 0.002742 & - & 0.0023941 & 0.0023595 \\
\hline
\end{tabular}

\section{CONCLUSIONS}

The structural analysis was performed, on a real existing sedan closed integral monocoque passenger car, by using dynamic load factors to represent the dynamic loading conditions imposed on the structural model to be nearly as the reality. Results revealed that the torsion loading case has higher internal forces and stresses in some members of the load paths than the corresponding bending loading case. The comparison between the theoretical and the calculated torsional stiffness of the overall car body structure in the optimization process for the combined torsion loading cases are almost consistent and enhanced through the optimization process, as shown in Fig. 14.

Although both the bending and torsion best optimization results give smaller DVs values, they take values near the starting in the final manual selection because of constraints on "DVs" imposed on them as follows:

1 - Beam thickness\# 3 (engine cross-member) because of bunching and fatigue imposed on it during operation.

2 - Shell thickness\# 4 (Floor panel assembly) because of having sufficient stiffness for the payload and other point-loads acting perpendicular on it, which are corrugated at some local areas.

The torsion optimization analysis results are affected by an increase in 'Beam thickness' which include the following beams (Front wheel panel upper beam, Inner front bulkhead beam, A-pillar upper and lower beams, Front windscreen upper and lower beams, Rear windscreen upper and lower beams, Upper sill beam (Roof), and D-pillar upper and lower beams) which form stiffening closed box of the passenger compartment. 
The comparison between the total car volume, which is a function of its weight reveals that a decay in its values through the optimization process. Fig. 15. Shows a comparison between the total car volume in both Torsion and Bending optimization processes.

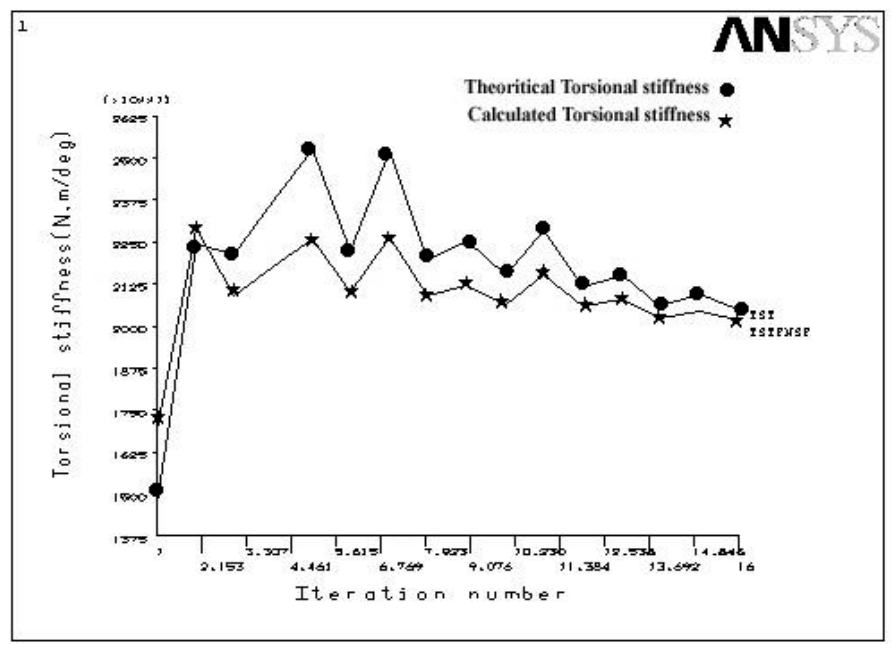

Fig .14.Comparisons between the calculated and theoretical total torsional stiffness variation during optimization looping, Torsion Case.

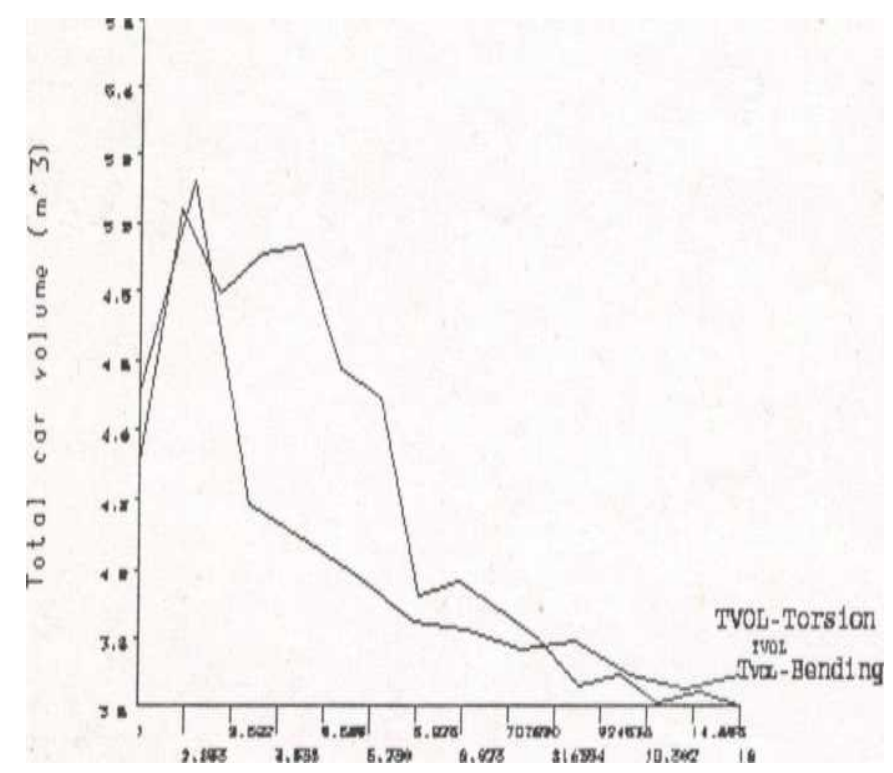

Fig .15.Comparison between the total car volume variation during optimizationlooping in both Bending and Torsion cases.

\section{REFERENCES}

[1] John Fenton, 'Handbook of Vehicle Design Analysis', SAE PUBLICATIONS, ISBN: 1-56091-903-5, 1996, U.K.

[2] Jornsen Reimpell and Helmut Stoll, "The Automotive Chassis: Engineering Principles”, ARNOLD, ISBN: 0-34061-443-9,1996, U.K.

[3] Janusz Pawlowski, "Vehicle Body Engineering", BUSINESS BOOKS LIMITED, ISBN: 0-22068-916-4, 1969, U.K.

[4] Jason C. Brown, A and John Robertson, "Motor Vehicle Structures: Concepts \& Fundamentals", BUTTERWORTH HEINEMANN, ISBN: 0-75065-134- 2,2002, U.K.

[5] John Fenton, "Vehicle Body Layout And Analysis", MECHANICAL ENGINNERING PUBLICATIONS LTD, ISBN: 0-85298-445-6,1980, U.K.

[6] Mounir M. Kamal and Joseph A. Wolf, "Modern Automotive Structural Analysis", VAN NOSTRAND REINHOLD COMPANY,ISBN:0 - 4224 $-839-3,1982$, USA

[7] Harry H. west, "Fundamental of Structural Analysis", JOHN WILEY AND SONS, ISBN:0 - 47151 - 354 - 7,1993, U.S.A.

[8] Marco Gadola, Silvio Granzotto, "Structural analysis of a lightweight,Aluminum -cladded racing car frame: experimental and numerical results" 3rd International Conference on Boundary and Finite Elements - ELFIN 3, Constanza, Romania, May 1995.

[9] C.J.Cooke, "Torsional stiffness analysis of car bodies", Institution of Mechanical Engineers-Proceedings 1965-66 Volume 180-Part 2A pp2344, U.K. 